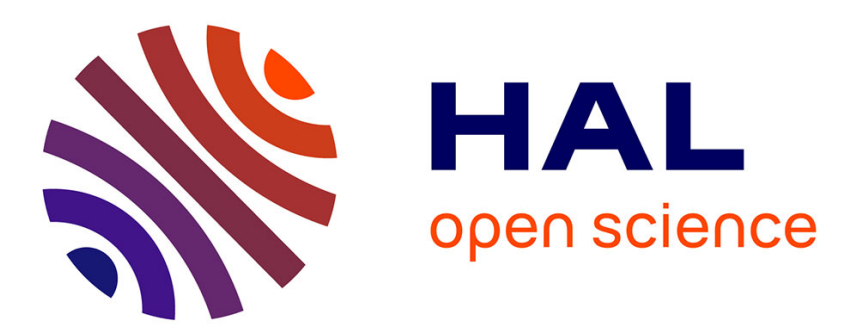

\title{
TTHE INFLUENCE OF DIAGNOSTIC CRITERIA ON THE INTERPRETATION OF ADRENAL VEIN SAMPLING
}

Gaëlle Lethielleux, Laurence Amar, Alain Raynaud, Pierre-François Plouin, Olivier Steichen

\section{To cite this version:}

Gaëlle Lethielleux, Laurence Amar, Alain Raynaud, Pierre-François Plouin, Olivier Steichen. TTHE INFLUENCE OF DIAGNOSTIC CRITERIA ON THE INTERPRETATION OF ADRENAL VEIN SAMPLING. Hypertension, 2015, 65 (4), pp.849-854. 10.1161/HYPERTENSIONAHA.114.04812 . hal-02503410

\section{HAL Id: hal-02503410 https://hal.sorbonne-universite.fr/hal-02503410}

Submitted on 9 Mar 2020

HAL is a multi-disciplinary open access archive for the deposit and dissemination of scientific research documents, whether they are published or not. The documents may come from teaching and research institutions in France or abroad, or from public or private research centers.
L'archive ouverte pluridisciplinaire HAL, est destinée au dépôt et à la diffusion de documents scientifiques de niveau recherche, publiés ou non, émanant des établissements d'enseignement et de recherche français ou étrangers, des laboratoires publics ou privés. 


\section{Hypertension}

\section{Manuscript Submission and Peer Review System}

Disclaimer: The manuscript and its contents are confidential, intended for journal review purposes only, and not to be further disclosed.

URL: http://hype-submit. aha-journals.org

Title: THE INFLUENCE OF DIAGNOSTIC CRITERIA ON THE INTERPRETATION OF

ADRENAL VEIN SAMPLING

Manuscript number: HYPE201404812R3

Author(s): Olivier Steichen, AP-HP, Hôpital Tenon

Gaëlle Lethielleux, AP-HP, HEGP

Amar Laurence, AP-HP, HEGP

Alain Raynaud, Alleray Labrouste clinic

Pierre-François Plouin, Hôpital Européen Georges Pompidou 


\section{THE INFLUENCE OF DIAGNOSTIC CRITERIA ON THE INTERPRETATION OF ADRENAL VEIN SAMPLING}

Gaëlle Lethielleux, Laurence Amar, Alain Raynaud, Pierre-François Plouin, Olivier Steichen

Assistance Publique-Hôpitaux de Paris (AP-HP), Georges Pompidou European Hospital, Hypertension Unit (G.L., L.A., P.-F.P.), and Cardiovascular Imaging Department (A.R.), F75015 Paris, France; Sorbonne Paris Cité, Université Paris Descartes (L.A., P.-F.P.), Faculty of Medicine, F-75006 Paris, France; AP-HP, Tenon Hospital (O.S.), Internal Medicine Department, F-75020 Paris, France; Sorbonne Universités, UPMC Univ Paris 06 (O.S.), Faculty of Medicine, F-75006 Paris, France; and Inserm, UMR_S1142 (O.S.), LIMICS, F75006 Paris, France

Short title: Diagnostic criteria of adrenal venous sampling

Word count of manuscript: 5960

Word count of abstract: 249

Number of figures: 0

All correspondence and requests to: Olivier Steichen,

Service de Médecine Interne, Hôpital Tenon,

4 rue de la Chine, F-75020 Paris, France.

Tel. +33 1560178 31; Fax +33 1560170 82; E-mail: olivier.steichen@tnn.aphp.fr. 


\begin{abstract}
Guidelines promote the use of adrenal vein sampling to document lateralized aldosterone hypersecretion in primary aldosteronism. However, there are large discrepancies between institutions in the criteria used to interpret its results. This study evaluates the consequences of these differences on the classification and management of patients. The results of all 537 adrenal venous sampling performed between 01/2001 and 07/2010 in our institution were interpreted with four diagnostic criteria used in experienced institutions where adrenal vein sampling is performed without cosyntropin (Brisbane, Padua, Paris, and Turin), and with criteria proposed by a recent consensus statement. Adrenal vein sampling were classified as unsuccessful, lateralized, or not lateralized according to each set of criteria. Almost five times more adrenal vein sampling were classified as unsuccessful with the strictest criteria than with the least strict criteria ( $18 \%$ versus $4 \%$, respectively). Similarly, over two times more adrenal vein sampling were classified as lateralized with the least stringent criteria than with the most stringent criteria (60\% versus $26 \%$, respectively). Multiple samples were available from at least one side for 155 adrenal vein sampling. These procedures were classified differently by at least two right-left sample pairs in $12 \%$ to $20 \%$ of cases. Thus, different sets of criteria used to interpret adrenal vein sampling in experienced institutions translate into heterogeneous classifications, and hence management decisions, for patients with primary aldosteronism. Defining the most appropriate procedures and diagnostic criteria is needed for adrenal vein sampling to achieve optimal performance and fully justify its status as a gold standard.
\end{abstract}

\title{
Keywords
}

Hyperaldosteronism; peripheral venous catheterization; adrenal glands, blood supply; differential diagnosis; reproducibility of results 
Patients with primary aldosteronism (PA) have either bilateral (idiopathic hyperplasia) or unilateral (aldosterone-producing adenoma [APA] or unilateral hyperplasia) adrenal disease. $^{1,2}$ Localizing the source of excessive aldosterone secretion is critical to select the appropriate therapy. Unilateral PA can be treated by laparoscopic adrenalectomy, which normalizes serum potassium concentrations in almost all cases and cures or improves hypertension in over $80 \%$ of patients. ${ }^{3,4}$ By contrast, medical management with mineralocorticoid receptor antagonists is recommended as the first-line treatment in bilateral PA. $^{5}$

Adrenal vein sampling (AVS) is currently considered the gold-standard to differentiate unilateral from bilateral aldosterone hypersecretion and is recommended in almost all patients with PA who are eligible for surgical management. ${ }^{5,6}$ The accuracy of catheter placement in the adrenal veins can be verified from the cortisol concentration in the adrenal veins divided by that in the inferior vena cava (IVC) or peripheral vein (selectivity index [SI]). If the SI reaches the predefined cut-off, the lateralization index (LI) is then used to classify PA into unilateral or bilateral disease. The LI is defined as the highest aldosterone/cortisol concentration ratio (dominant adrenal vein) divided by the lowest aldosterone/cortisol concentration ratio (non-dominant adrenal vein). Some investigators also propose the use of the contralateral suppression index (CSI), defined by the aldosterone/cortisol concentration ratio of the non-dominant adrenal vein divided by the peripheral aldosterone/cortisol concentration ratio. ${ }^{7}$ However, the protocol of AVS (simultaneous or sequential bilateral AVS, use of cosyntropin or not, and the protocol of cosyntropin infusion), and the SI and LI cut-offs used to interpret the results are not currently standardized. ${ }^{7-9}$

We interpreted a large number of AVS with criteria used in four reference centers or proposed by a recent consensus statement. ${ }^{6,10-12}$ The first objective of this study was to examine to which extent the interpretation of AVS may differ according to the criteria used for its 
interpretation. The second goal was to assess the reproducibility of this interpretation when multiple blood samples were drawn from the same adrenal vein.

\section{Methods}

\section{Patients}

This retrospective study included all patients who underwent AVS in our hypertension referral center between January 2001 and July 2010. Clinical, biochemical, hormonal and radiological data were extracted from the electronic health record database. Patients were initially referred for tests because they had resistant or hypokalemic hypertension, or suspected PA. Our methods for diagnosing PA have been described previously. ${ }^{13}$ Plasma aldosterone and active renin concentrations, and urinary aldosterone concentrations were measured at least two weeks after the discontinuation of interfering antihypertensive drugs whenever possible (six weeks for mineralocorticoid receptor antagonists and aliskiren). If necessary, calcium-antagonists and alpha-blockers were prescribed to control high blood pressure in patients with severe hypertension. Patients with persistent hypokalemia were given $3-6 \mathrm{~g}$ of potassium chloride daily to maintain serum potassium concentrations $\geq 3.5$ $\mathrm{mmol} / \mathrm{L}$, and unrestricted dietary sodium intake was recommended.

A plasma aldosterone/renin ratio (ARR) cut-off value of $64 \mathrm{pmol} / \mathrm{mUI}$ on two occasions was used as a screening test. The minimum active renin concentration was set at $5 \mathrm{mUI} / \mathrm{L}$ for this calculation, to avoid overestimating ARR due to undetectable concentrations of active renin. If the ARR exceeded $64 \mathrm{pmol} / \mathrm{mUI}$, the diagnosis of PA was based on a recumbent plasma aldosterone concentration $>500 \mathrm{pmol} / \mathrm{L}$, a sitting plasma aldosterone concentration $>550$ $\mathrm{pmol} / \mathrm{L}$ or a urinary excretion of aldosterone $>63 \mathrm{nmol} / 24 \mathrm{~h}$.

Before 2008, AVS was reserved for patients with a diagnosis of PA and equivocal imaging studies (without a typical solitary adenoma). However, since 2008 a suppression test (the 
saline infusion test) and AVS have been systematically performed for all PA patients eligible for surgery, according to guidelines from the Endocrine Society. ${ }^{5}$ All patients underwent an abdominal computed tomography (CT) scan or magnetic resonance imaging (MRI) before AVS. The retrospective use of anonymous patient data collected during routine care and the procedures followed for this study are in accordance with French institutional guidelines.

\section{AVS protocol}

AVS were performed under the same standardized conditions used for PA diagnosis. Mineralocorticoid receptor antagonists were systematically discontinued. However, $25-30 \%$ of patients were assessed without the complete withdrawal of other interfering antihypertensive medication, due to severe hypertension. ${ }^{14}$ Bilateral simultaneous AVS without cosyntropin stimulation was performed in the morning after a night's sleep the in supine position, by the same experienced vascular radiologist over the ten-year period (A. R.). Two catheters were inserted via the femoral vein and their correct placement was verified before sampling by the injection of a small amount of contrast agent. Blood samples were then collected simultaneously from each adrenal vein and the IVC, for the measurement of cortisol and aldosterone concentrations. If the radiologist had any doubt about the catheter placement during the procedure, a second or even a third sample was collected.

\section{Diagnostic criteria}

We used Medline to search for papers providing precise descriptions of protocols and diagnostic criteria used to carry out AVS without cosyntropin at other centers between 2001 and 2010. This identified three centers: Brisbane, Padua and Turin. ${ }^{10-12}$ We also used the criteria proposed by a recent consensus statement. ${ }^{6}$ Each AVS performed in our unit between January 2001 and July 2010 was analyzed according to the four different sets of criteria reported in Table 1. 
AVS were classified as: (i) unsuccessful if they did not meet the criterion of selective AVS;

(ii) lateralized on the left or right side, if successful and meeting the criteria for lateralization on the considered side; or (iii) not lateralized, if successful but not meeting the criteria for lateralization. For AVS with multiple samples available from at least one adrenal vein, we compared the classification resulting from the use of the arithmetic mean of all aldosterone/cortisol concentration ratios on the same side, the most selective sample on each side, or all possible pairs of left and right side selective samples.

\section{Measurements}

Blood pressure was recorded three times with a semi-automatic manometer (Omron $705 \mathrm{CP})$, in the lying-position, with a 5 minute rest period before measurements. ${ }^{15}$ Sodium and potassium concentrations were measured by a standard method. The glomerular filtration rate was estimated (eGFR) by the 4 variables Modification of Diet in Renal Disease (MDRD) Study equation. Active renin concentrations were determined by a chemiluminescent immunoassay (LIAISON; Diasorin, Antony, France) and aldosterone concentrations were determined by radioimmunoassay (Coat-A-Count; Siemens Medical Solutions Diagnostics, Saint-Denis, France). The urinary excretion of aldosterone was calculated from free aldosterone and aldosterone from the hydrolysis of aldosterone 18-glucuronide at $\mathrm{pH} 1$.

\section{Statistical analysis}

Descriptive statistics are reported as percentages or medians [interquartile range], as appropriate, and differences were evaluated by the Fisher or the Mann-Whitney tests, respectively. 
Each AVS was classified according to each set of diagnostic criteria. The arithmetic mean of aldosterone/cortisol concentration ratios was chosen as the default method to handle multiple selective samples from the same side.

The impact of the approach used to handle multiple selective samples from the same side (arithmetic mean, consideration of the sample with the highest SI only) was evaluated in terms of AVS interpretation in each center. The reproducibility of AVS with each set of criteria was evaluated using AVS with multiple selective samples from at least one side. All possible combinations of selective samples were used to simulate all LI that could have resulted by chance if only one selective sample had been available on each side. The LI most favorable to the left adrenal vein was then compared with the LI most favorable to the right side to evaluate the maximum discordance between samples.

The concordance of the classifications between or within centers was assessed with kappa coefficients. ${ }^{16}$ All analyses were performed with Stata 9.2 (StataCorp, College Station, Texas).

\section{Results}

\section{Patient characteristics}

A total of 537 AVS were performed in 526 patients in our institution between January 2001 and July 2010. Relevant clinical, biochemical and radiological features of the patients are reported in Table 2 .

\section{Interpretation of AVS}

The proportion of unsuccessful AVS was almost five times higher with the strictest criteria (18\% with the Brisbane criteria, SI $\geq 3$ ) than with the most lenient criteria (4\% with the Padua criteria, SI $\geq 1.1$ ). Over two times more AVS were classified as lateralized with the least 
stringent criteria $(60 \%$ with the Padua criteria, $L I \geq 2)$ than with the most stringent criteria ( $26 \%$ with the Brisbane criteria, LI' $\geq 2$ and CSI $<1$ ) among patients with successful AVS. The analysis of AVS according to each set of criteria is shown in Table 1.

Only $56 \%$ of the AVS in the whole cohort were classified identically by all diagnostic criteria (19 (4\%) as unselective, $55(10 \%)$ as lateralized to the right, $63(12 \%)$ as lateralized to the left and $165(31 \%)$ as not lateralized) and $40 \%$ of AVS interpretation were discordant between the two most extreme sets of diagnostic criteria (Padua and Brisbane). The highest concordance level (92\%) was observed between Turin and Paris, the two centers with the closest SI and LI (Table 3).

\section{Use of the most selective among multiple samples}

Multiple blood samples were available from at least one side for 155 of the 537 AVS (29\%). After the application of SI from each center, multiple selective samples were available from at least one side for 155 (29\%) of AVS according to Padua criteria, 142 (26\%) according to Turin, Paris or consensus criteria, and 132 (25\%) according to Brisbane criteria.

We used the aldosterone/cortisol concentration ratio from the most selective sample on each side instead of the mean of the ratios from all selective samples to compute the LI and interpret these 155 AVS. The disagreements and kappa coefficients between both interpretations are shown in Table 4 for each set of criteria. In all cases of disagreement, the interpretation changed from lateralized to non-lateralized or vice versa but never from lateralized on one side to lateralized on the other.

\section{Between-sample reproducibility}

We then computed the two most discordant interpretations that could have occurred if only one sample had been available on each side for the 155 AVS with multiple selective samples. 
The disagreements and kappa coefficients between these two most extreme possible interpretations are shown in Table 4 for each set of criteria. The majority of disagreements involved changes from lateralized to non-lateralized or vice versa. However, 4/31 disagreements with Padua criteria and 3/30 with consensus criteria involved changes from lateralized on one side to lateralized on the other.

\section{Discussion}

AVS is currently considered the gold-standard test to diagnose unilateral aldosterone excess in PA. ${ }^{5}$ This procedure will be increasingly used, given the raising detection rate of PA. ${ }^{17}$ However, it is an invasive and expensive procedure that may result in complications, ${ }^{18}$ and thus should only be used if it provides reliable and useful diagnostic information. Our findings reveal that the interpretation of AVS may differ according to the criteria used for its analysis, suggesting that some patients may be misdiagnosed and improperly managed due to a lack of standardization.

\section{Comparison with previous studies and interpretation of our results}

Kline et al. compared ten different AVS protocols (with or without cosyntropin stimulation) in 63 patients. ${ }^{19}$ The success rate of AVS ranged between $13 \%$ and $77 \%$, according to the SI used, and only $17 \%$ of patients were uniformly classified by all diagnostic criteria ( $8 \%$ as having bilateral aldosterone excess and $9 \%$ as having unilateral aldosterone excess). Mulatero et al. reviewed 64 patients who had undergone AVS twice, because the first procedure was unsuccessful according to stringent criteria. ${ }^{9}$ The analysis of these AVS results with two other sets of diagnostic criteria revealed poor agreement $(35 \%)$ between the interpretation of the first and second AVS with the most lenient set of criteria (including 14\% of AVS changing from unilateral in one side to unilateral in the contralateral side). 
These results are consistent with our findings and show that the choice of SI and LI strongly affects the interpretation of AVS and subsequent therapeutic decisions: the same AVS may be considered selective and lateralized in one center, non-selective in a second center and selective but not lateralized in a third center, leading to radically different patient management.

The arithmetic mean is usually used to average aldosterone to cortisol ratios from multiple selective samples from the same adrenal vein. Another option is to retain only the sample with the highest SI from each adrenal vein, because the SI measures sampling quality. Our results show that this choice may affect the interpretation of AVS, although we are unable to determine which interpretation is more accurate.

The concordance between the two most discrepant AVS interpretation criteria (Padua and Brisbane) was similar to that reported between AVS and adrenal imaging in a meta-analysis of 38 studies. ${ }^{20}$ Discordance between AVS and adrenal imaging is commonly attributed to adrenal incidentalomas that may coexist with bilateral hyperplasia, or to small adenomas or unilateral hyperplasia that are not detected by imaging. ${ }^{12,20-22}$ However, discordance may also be caused by the failure or misinterpretation of AVS. Aldosterone hypersecretion, ${ }^{23-26}$ and even non suppressible aldosterone hypersecretion, ${ }^{27}$ may persist after adrenalectomy on the basis of AVS results. Such outcomes indicate erroneously lateralized AVS. In rare cases, patients have been hormonally cured after adrenalectomy on the side of a typical Conn adenoma, despite AVS indicating bilateral PA or unilateral PA in the opposite side. ${ }^{28,29}$ Despite these disturbing reports, the clinical consequences of the inaccurate interpretation of AVS are uncertain. Mineralocorticoid receptor antagonists can correct hypertension and hypokalemia in unilateral PA. ${ }^{30}$ Thus, the main problem arises when a lateralized AVS leads to unjustified surgery because of bilateral or, even more concerning, contralateral disease. Our results show that this possibility may occur with the most lenient selectivity criteria. 


\section{Practical implications}

Many authors have attempted to measure diagnostic accuracy of AVS. ${ }^{31,32}$ However, false negatives may go unnoticed because patients without diagnosed lateralized hypersecretion do not undergo surgery. ${ }^{33}$ False positives may also go unnoticed because it is very difficult to determine whether PA has been cured after surgery: essential hypertension can persist after adrenalectomy in unilateral PA. ${ }^{34,35}$ Postoperative suppression tests are therefore necessary to ascertain postoperative cure of PA but are consistently performed in a few reference centers only. Consequently, neither the sensitivity nor the specificity of AVS can be accurately estimated.

The same methodological concerns apply to the determination of the best set of interpretation criteria. Theoretically, the optimal SI and LI thresholds should be determined as the strongest predictors of post-surgical cure in a group of patients with PA all operated on, irrespective of their AVS results. ${ }^{6}$ However, such a study would be unethical. Mulatero et al. propose that the best thresholds are those that achieve the most reproducible classification in patients subjected to two AVS. ${ }^{9}$ This predictably leads to the adoption of the strictest set of criteria. Pragmatic considerations also hint toward this direction. Indeed, surgical treatment of bilateral PA is probably less desirable than medical treatment of unilateral PA. Hence, false negatives of AVS are less of a concern than false positives and high diagnostic thresholds seem preferable. Although the best value of the thresholds is unknown, it is nonetheless problematic that patients with the same AVS results may not receive the same treatment in two different reference centers. Ideally, diagnostic criteria should be standardized across centers.

Moreover, it is common practice to take duplicate blood samples during AVS and there is no consensus about what sample should be used or how they should be combined. These factors may further increase the heterogeneity of AVS interpretation. In our study, the strictest 
criteria (Brisbane) resulted in the highest reproducibility between multiple samples. This finding strengthens the idea that stringent diagnostic thresholds are preferable. However, it is still unclear whether the use of the CSI (as implemented in Brisbane) improves the diagnostic accuracy of AVS in cases where the LI is high. Indeed, the lack of contralateral suppression was not associated with a lower rate of response to adrenalectomy in patients with a LI > 4 in a recent study. ${ }^{36}$

The limited between samples concordance observed in our study challenge previous results showing a high concordance between single and duplicate sampling. ${ }^{37}$ Variability of the aldosterone/cortisol concentration ratio between samples from the same adrenal vein could have resulted in different interpretation with the same set of criteria if only one of these samples had been available, resulting in the same patient receiving different treatments in the same reference center depending on the available sample.

\section{Limitations}

Some limitations of our study need to be highlighted. First, the analysis is retrospective, but the data were recorded prospectively and few values were missing in the electronic database. Second, some patients underwent AVS without the withdrawal of interfering antihypertensive medications. Renin unsuppression could theoretically lead to non-lateralized AVS despite unilateral disease; this would affect interpretations with strict criteria more than interpretations with lenient criteria and may therefore increase the number of discordances. However, using potent antihypertensive drugs in high-risk patients matches real-life practice and some studies suggest that AVS remains informative in patients taking interfering drugs and even in those taking spironolactone. ${ }^{6,38}$ Third, we performed bilateral simultaneous AVS whereas the three other centers perform sequential AVS. Since simultaneous sampling abolishes a source of variability, our results may underestimate the true overall variability of 
AVS results between centers. However, the other centers report a gap less than 10 to 15 minutes between sampling of the two adrenal veins and this source of variability is probably minimal. Fourth, we used a RIA assay for aldosterone measurements and using mass spectrometry may decrease analytical variability and between-sample variability. Fifth, the design of our study does not enable us to provide recommendations about the optimal SI and LI that should be used, or about potential improvements (like using metanephrines instead of cortisol for computing the SI) or alternatives to AVS (like functional imaging with ${ }^{11} \mathrm{C}$ metomidate).

\section{Perspectives}

AVS is currently considered the reference test for assessing the lateralization of aldosterone hypersecretion in primary aldosteronism, and is considered preferable to imaging. However, its results should be interpreted with caution because cut-offs determining the success of adrenal sampling and the lateralization of hypersecretion are not standardized. Different criteria currently used in experienced institutions translate into heterogeneous classifications and hence management decisions for PA patients (with discordance in up to $40 \%$ of AVS). Moreover, the true specificity and sensitivity of AVS are unknown, and evidence of its superiority over adrenal imaging is methodologically weak due to the lack of independent gold standard. Standardization is a prerequisite to collaborative research and to the evaluation of the diagnostic and prognostic value of AVS. A recent expert consensus statement on the interpretation of AVS proposed a cut-off value of SI $\geq 2$ and LI $\geq 2$ under unstimulated conditions and SI $\geq 3$ and $\mathrm{LI} \geq 4$ during cosyntropin stimulation. ${ }^{6}$ This consensus may allow the interpretation of AVS to be standardized across centers, although the use of cosyntropin, the usefulness of multiple blood samples from the same vein (and the best way to handle them), and even the true diagnostic value of AVS remain uncertain. As a further note of 
caution, the LI $\geq 2$ under unstimulated conditions led three of our AVS with multiple selective samples to be possibly interpreted both as lateralized to the left or lateralized to the right, depending on the samples used for the LI calculation. This undesirable behavior does not occur in our AVS with multiple samples when the LI threshold is $\geq 3$.

\section{Sources of funding}

None

\section{Disclosures}

None 


\section{References}

1. Chao C-T, Wu V-C, Kuo C-C, Lin Y-H, Chang C-C, Chueh SJ, Wu K-D, Pimenta E, Stowasser M. Diagnosis and management of primary aldosteronism: an updated review. Ann Med. 2013;45:375-383.

2. Amar L, Plouin P-F, Steichen O. Aldosterone-producing adenoma and other surgically correctable forms of primary aldosteronism. Orphanet J Rare Dis. 2010;5:9.

3. Letavernier E, Peyrard S, Amar L, Zinzindohoué F, Fiquet B, Plouin P-F. Blood pressure outcome of adrenalectomy in patients with primary hyperaldosteronism with or without unilateral adenoma. J Hypertens. 2008;26:1816-1823.

4. Steichen O, Zinzindohoué F, Plouin P-F, Amar L. Outcomes of adrenalectomy in patients with unilateral primary aldosteronism: a review. Horm Metab Res. 2012;44:221-227.

5. Funder J, Carey R, Fardella C, Gomez-Sanchez C, Mantero F, Stowasser M, Young W, Montori VM. Case detection, diagnosis, and treatment of patients with primary aldosteronism: an Endocrine Society clinical practice guideline. J Clin Endocrinol Metab. 2008;93:3266-3281.

6. Rossi GP, Auchus RJ, Brown M, Lenders JWM, Naruse M, Plouin PF, Satoh F, Young WF. An expert consensus statement on use of adrenal vein sampling for the subtyping of primary aldosteronism. Hypertension. 2014;63:151-160.

7. Rossi GP, Barisa M, Allolio B, Auchus RJ, Amar L, Cohen D, Degenhart C, Deinum J, Fischer E, Gordon R, Kickuth R, Kline G, Lacroix A, Magill S, Miotto D, Naruse M, Nishikawa T, Omura M, Pimenta E, Plouin P-F, Quinkler M, Reincke M, Rossi E, Rump 
LC, Satoh F, Schultze Kool L, Seccia TM, Stowasser M, Tanabe A, Trerotola S, Vonend O, Widimsky J, Wu K-D, Wu V-C, Pessina AC. The Adrenal Vein Sampling International Study (AVIS) for identifying the major subtypes of primary aldosteronism. J Clin Endocrinol Metab. 2012;97:1606-1614.

8. Graham UM, Mullan KR, Hunter SJ, Atkinson AB. Stewart PM and Allolio B. Adrenal vein sampling for primary aldosteronism: time for a reality check Response. Clin Endocrinol (Oxf). 2010;73:551-552.

9. Mulatero P, Bertello C, Sukor N, Gordon R, Rossato D, Daunt N, Leggett D, Mengozzi G, Veglio F, Stowasser M. Impact of different diagnostic criteria during adrenal vein sampling on reproducibility of subtype diagnosis in patients with primary aldosteronism. Hypertension. 2010;55:667-673.

10. Mulatero P, Bertello C, Rossato D, Mengozzi G, Milan A, Garrone C, Giraudo G, Passarino G, Garabello D, Verhovez A, Rabbia F, Veglio F. Roles of clinical criteria, computed tomography scan, and adrenal vein sampling in differential diagnosis of primary aldosteronism subtypes. J Clin Endocrinol Metab. 2008;93:1366-1371.

11. Stowasser M, Gordon RD, Rutherford JC, Nikwan NZ, Daunt N, Slater GJ. Diagnosis and management of primary aldosteronism. J Renin Angiotensin Aldosterone Syst. 2001;2:156-169.

12. Rossi GP, Sacchetto A, Chiesura-Corona M, De Toni R, Gallina M, Feltrin GP, Pessina AC. Identification of the etiology of primary aldosteronism with adrenal vein sampling in patients with equivocal computed tomography and magnetic resonance findings: results in 104 consecutive cases. J Clin Endocrinol Metab. 2001;86:1083-1090. 
13. Küpers EM, Amar L, Raynaud A, Plouin P-F, Steichen O. A clinical prediction score to diagnose unilateral primary aldosteronism. J Clin Endocrinol Metab. 2012;97:35303537.

14. Steichen O, Blanchard A, Plouin P-F. Assessment of serum sodium to urinary sodium divided by (serum potassium) ${ }^{2}$ to urinary potassium as a screening tool for primary aldosteronism. Eur J Clin Invest. 2011;41:189-194.

15. La Batide-Alanore A, Chatellier G, Bobrie G, Fofol I, Plouin PF. Comparison of nurseand physician-determined clinic blood pressure levels in patients referred to a hypertension clinic: implications for subsequent management. J Hypertens. 2000;18:391-398.

16. Cohen J. A coefficient of agreement for nominal scales. Educ Psychol Meas. 1960;20:37-46.

17. Mulatero P, Stowasser M, Loh K-C, Fardella CE, Gordon RD, Mosso L, GomezSanchez CE, Veglio F, Young WF. Increased diagnosis of primary aldosteronism, including surgically correctable forms, in centers from five continents. J Clin Endocrinol Metab. 2004;89:1045-1050.

18. Daunt N. Adrenal vein sampling: how to make it quick, easy, and successful. Radiographics. 2005;25 Suppl 1:S143-158.

19. Kline GA, Harvey A, Jones C, Hill MH, So B, Scott-Douglas N, Pasieka JL. Adrenal vein sampling may not be a gold-standard diagnostic test in primary aldosteronism: final diagnosis depends upon which interpretation rule is used. Variable interpretation of adrenal vein sampling. Int Urol Nephrol. 2008;40:1035-1043. 
20. Kempers MJE, Lenders JWM, van Outheusden L, van der Wilt GJ, Schultze Kool LJ, Hermus ARMM, Deinum J. Systematic review: diagnostic procedures to differentiate unilateral from bilateral adrenal abnormality in primary aldosteronism. Ann Intern Med. 2009;151:329-337.

21. Omura M, Sasano H, Saito J, Yamaguchi K, Kakuta Y, Nishikawa T. Clinical characteristics of aldosterone-producing microadenoma, macroadenoma, and idiopathic hyperaldosteronism in 93 patients with primary aldosteronism. Hypertens Res. 2006;29:883-889.

22. Terzolo M, Stigliano A, Chiodini I, Loli P, Furlani L, Arnaldi G, Reimondo G, Pia A, Toscano V, Zini M, Borretta G, Papini E, Garofalo P, Allolio B, Dupas B, Mantero F, Tabarin A, Italian Association of Clinical Endocrinologists. AME position statement on adrenal incidentaloma. Eur J Endocrinol. 2011;164:851-870.

23. Zarnegar R, Lee J, Brunaud L, Lindsay S, Kebebew E, Clark OH, Duh Q-Y. Good blood pressure control on antihypertensives, not only response to spironolactone, predicts improved outcome after adrenalectomy for aldosteronoma. Surgery. 2007;142:921-929; discussion 921-929.

24. Ishidoya S, Kaiho Y, Ito A, Morimoto R, Satoh F, Ito S, Ishibashi T, Nakamura Y, Sasano H, Arai Y. Single-center outcome of laparoscopic unilateral adrenalectomy for patients with primary aldosteronism: lateralizing disease using results of adrenal venous sampling. Urology. 2011;78:68-73.

25. Auchus RJ, Wians FH, Anderson ME, Dolmatch BL, Trimmer CK, Josephs SC, Chan D, Toomay S, Nwariaku FE. What we still do not know about adrenal vein sampling for primary aldosteronism. Horm Metab Res. 2010;42:411-415. 
26. Van der Linden P, Steichen O, Zinzindohoué F, Plouin P-F. Blood pressure and medication changes following adrenalectomy for unilateral primary aldosteronism: a follow-up study. J Hypertens. 2012;30:761-769.

27. Stowasser M, Gordon RD. Primary aldosteronism--careful investigation is essential and rewarding. Mol Cell Endocrinol. 2004;217:33-39.

28. White ML, Gauger PG, Doherty GM, Cho KJ, Thompson NW, Hammer GD, Miller BS. The role of radiologic studies in the evaluation and management of primary hyperaldosteronism. Surgery. 2008;144:926-933; discussion 933.

29. Zelinka T, Mašek M, Vlková J, Kasalický M, Michalský D, Holaj R, Petrák O, Štrauch B, Rosa J, Dvořáková J, Widimský J. Discrepant results of adrenal venous sampling in seven patients with primary aldosteronism. Kidney Blood Press Res. 2012;35:205-210.

30. Catena C, Colussi G, Lapenna R, Nadalini E, Chiuch A, Gianfagna P, Sechi LA. Longterm cardiac effects of adrenalectomy or mineralocorticoid antagonists in patients with primary aldosteronism. Hypertension. 2007;50:911-918.

31. Young WF, Stanson AW, Thompson GB, Grant CS, Farley DR, van Heerden JA. Role for adrenal venous sampling in primary aldosteronism. Surgery. 2004;136:1227-1235.

32. Doppman JL, Gill JR, Miller DL, Chang R, Gupta R, Friedman TC, Choyke PL, Feuerstein IM, Dwyer AJ, Jicha DL. Distinction between hyperaldosteronism due to bilateral hyperplasia and unilateral aldosteronoma: reliability of CT. Radiology. 1992;184:677-682.

33. Nwariaku FE, Miller BS, Auchus R, Holt S, Watumull L, Dolmatch B, Nesbitt S, Vongpatanasin W, Victor R, Wians F, Livingston E, Snyder WH. Primary 
hyperaldosteronism: effect of adrenal vein sampling on surgical outcome. Arch Surg. 2006;141:497-502; discussion 502-503.

34. Rossi GP, Bolognesi M, Rizzoni D, Seccia TM, Piva A, Porteri E, Tiberio GAM, Giulini SM, Agabiti-Rosei E, Pessina AC. Vascular remodeling and duration of hypertension predict outcome of adrenalectomy in primary aldosteronism patients. Hypertension. 2008;51:1366-1371.

35. Proye CA, Mulliez EA, Carnaille BM, Lecomte-Houcke M, Decoulx M, Wémeau JL, Lefebvre J, Racadot A, Ernst O, Huglo D, Carré A. Essential hypertension: first reason for persistent hypertension after unilateral adrenalectomy for primary aldosteronism? Surgery. 1998;124:1128-1133.

36. Monticone S, Satoh F, Viola A, Fischer E, Vonend O, Bernini G, Lucatello B, Quinkler M, Ronconi V, Morimoto R, Kudo M, Degenhart C, Gao X, Carrara D, Willenberg HS, Rossato D, Mengozzi G, Riester A, Paci E, Iwakura Y, Burrello J, Maccario M, Giacchetti G, Veglio F, Ito S, Reincke M, Mulatero P. Aldosterone Suppression on Contralateral Adrenal During Adrenal Vein Sampling does not Predict Blood Pressure Response After Adrenalectomy. J Clin Endocrinol Metab. 2014;99:4158-4166.

37. Dekkers T, Arntz MJ, van der Wilt GJ, Schultze Kool LJ, Sweep FCGJ, Hermus ARMM, Lenders JWM, Deinum J. Single versus duplicate blood samples in ACTH stimulated adrenal vein sampling. Clin Chim Acta. 2013;423:15-17.

38. Haase M, Riester A, Kröpil P, Hahner S, Degenhart C, Willenberg HS, Reincke M. Outcome of adrenal vein sampling performed during concurrent mineralocorticoid receptor antagonist therapy. J Clin Endocrinol Metab. 2014;99:4397-4402. 


\section{Novelty and significance}

\section{What is new?}

- The analysis of a large number of results from adrenal vein sampling with different diagnostic criteria reveals that the interpretation of the same AVS can substantially differ between centers with different criteria.

- If multiple samples are available from at least one adrenal vein, the interpretation with permissive criteria can change from lateralized on one side to lateralized on the other side, depending on the samples used.

\section{What is relevant?}

- Our results suggest that the management of PA patients frequently differs between centers, depending on the criteria used to interpret AVS.

- The disagreement between strict and lenient interpretation criteria of AVS in our study is as high as the disagreement between AVS and adrenal imaging in previous studies, which is frequently taken as evidence against the use of imaging.

\section{Summary}

We reinterpreted 537 adrenal vein sampling procedures performed in one center with diagnostic criteria from three other experienced institutions. The number of selective and lateralized procedures differed greatly depending on the criteria. Only $56 \%$ of AVS were classified identically by all sets of criteria. 
Table 1. Interpretation criteria and classification of AVS in the different centers

Lateralization of aldosterone hypersecretion

\begin{tabular}{lcccccc}
$\begin{array}{l}\text { Set of } \\
\text { criteria }\end{array}$ & $\begin{array}{c}\text { Selectivity } \\
\text { criterion }\end{array}$ & $\begin{array}{c}\text { Unsuccessful } \\
\text { AVS }\end{array}$ & $\begin{array}{c}\text { Lateralization } \\
\text { criteria }\end{array}$ & Bilateral & Left & Right \\
\hline Brisbane & SI $\geq 3$ & $99(18 \%)$ & $\begin{array}{c}\text { LI' } \geq 2 \text { and } \\
\text { CSI }<1\end{array}$ & $299(56 \%)$ & $80(15 \%)$ & $59(11 \%)$ \\
Padua & SI $\geq 1.1$ & $19(4 \%)$ & LI $\geq 2$ & $195(36 \%)$ & $176(33 \%)$ & $137(27 \%)$ \\
Paris & SI $\geq 2$ & $64(12 \%)$ & LI $\geq 5$ & $308(57 \%)$ & $87(16 \%)$ & $78(15 \%)$ \\
Turin & SI $\geq 2$ & $64(12 \%)$ & $\begin{array}{c}\text { LI } \geq 4 \text { or (LI } \geq \\
3 \text { and CSI }<1)\end{array}$ & $266(50 \%)$ & $113(21 \%)$ & $94(17 \%)$ \\
Consensus & SI $\geq 2$ & $64(12 \%)$ & LI $\geq 2$ & $174(32 \%)$ & $165(31 \%)$ & $134(25 \%)$ \\
\hline
\end{tabular}

$\mathrm{SI}=$ Selectivity Index $=$ Cortisol $_{\text {adrenal vein }} /$ Cortisol $_{\text {inferior vena cava }}$

$\mathrm{LI}=$ Lateralization Index $=(\text { Aldosterone } / \text { Cortisol })_{\text {dominant side }} /(\text { Aldosterone } / \text { Cortisol })_{\text {non-dominant }}$ side

$\mathrm{LI}^{\prime}=(\text { Aldosterone } / \text { Cortisol })_{\text {dominant side }} /(\text { Aldosterone/Cortisol })_{\text {inferior vena cava }}$

$\mathrm{CSI}=$ Controlateral Supression Index $=(\text { Aldosterone } / \text { Cortisol })_{\text {non-dominant side }} /$

(Aldosterone/Cortisol) inferior vena cava 
Table 2. Baseline characteristics of patients

Characteristics

Males

Age at (first) adrenal venous sampling (year)

Body mass index $\left(\mathrm{kg} / \mathrm{m}^{2}\right)$

Systolic blood pressure $(\mathrm{mmHg})$

Diastolic blood pressure $(\mathrm{mmHg})$

Serum potassium $(\mathrm{mmol} / \mathrm{L})$

Estimated glomerular filtration rate $\left(\mathrm{mL} / \mathrm{min} / 1.73 \mathrm{~m}^{2}\right)$

Plasma aldosterone (pmol/L)

Plasma active renin (mUI/L)

Aldosterone-to-renin ratio (pmol/mUI)

Urinary aldosterone (nmol/24h)

Antihypertensive drug classes (n)

Adrenal imaging*

typical unilateral adenoma

other unilateral lesions

bilateral lesions

apparently normal adrenal glands
Values

$343 / 524(65 \%)$

$48[41,54]$

$28[24.9,31.1]$

$149[136,160]$

$93[85,101]$

$3.4[3.1,3.7]$

$91[73,103]$

$539[367,790]$

$3[1,5]$

$94[65,140]$

$77[54,105]$

$2[1,3]$

$96 / 520(19 \%)$

$129 / 520(25 \%)$

$96 / 520(19 \%)$

$199 / 520(38 \%)$

Values are given as numbers (percentages) or medians [interquartile range].

* typical unilateral adenoma are radiolucent, smooth and $\geq 8 \mathrm{~mm}$; other unilateral lesions comprise unilateral hyperplasia or atypical adenoma; bilateral lesions comprise bilateral hyperplasia or bilateral adenomas. 
Table 3. Discordances between sets of criteria for AVS interpretation

\begin{tabular}{lcccccccccc}
$\begin{array}{l}\text { Sets of } \\
\text { criteria }\end{array}$ & $\begin{array}{c}\text { Brisbane } \\
\text { Padua }\end{array}$ & $\begin{array}{c}\text { Brisbane } \\
\text { Paris }\end{array}$ & $\begin{array}{c}\text { Brisbane } \\
\text { Turin }\end{array}$ & $\begin{array}{c}\text { Padua } \\
\text { Paris }\end{array}$ & $\begin{array}{c}\text { Padua } \\
\text { Turin }\end{array}$ & $\begin{array}{c}\text { Consensus } \\
\text { Padua }\end{array}$ & $\begin{array}{c}\text { Consensus } \\
\text { Paris }\end{array}$ & $\begin{array}{c}\text { Consensus } \\
\text { Turin }\end{array}$ & $\begin{array}{c}\text { Consensus } \\
\text { Brisbane }\end{array}$ & $\begin{array}{c}\text { Paris } \\
\text { Turin }\end{array}$ \\
\hline Disagreement & $40 \%$ & $16 \%$ & $17 \%$ & $33 \%$ & $26 \%$ & $9 \%$ & $25 \%$ & $17 \%$ & $31 \%$ & $8 \%$ \\
Kappa & 0.44 & 0.74 & 0.74 & 0.53 & 0.64 & 0.88 & 0.75 & 0.76 & 0.57 & 0.88 \\
\hline
\end{tabular}


Table 4. Impact of using the most selective sample only (A) and of between-sample variability (B) on the interpretation of the 155 AVS with multiple selective samples on at least one side, according to each set of criteria

\begin{tabular}{lccccc} 
Set of criteria & Brisbane & Padua & Paris & Turin & Consensus \\
\hline \multicolumn{2}{l}{ A. Most selective sample vs. mean of all selective samples on each side } \\
Disagreement & $6 \%$ & $10 \%$ & $5 \%$ & $6 \%$ & $8 \%$ \\
Kappa & 0.89 & 0.85 & 0.91 & 0.91 & 0.88 \\
\\
B. Two most extreme left-right pairs of selective samples \\
$\begin{array}{l}\text { Disagreement } \\
\text { Kappa }\end{array}$ & $12 \%$ & $20 \%$ & $15 \%$ & $16 \%$ & $19 \%$ \\
\hline
\end{tabular}

